\title{
Synthetic Cathinone Analogues Structurally Related to the Central Stimulant Methylphenidate as Dopamine Reuptake Inhibitors
}

Barkha J. Yadav-Samudrala, ${ }^{\dagger}$ Jose M. Eltit, ${ }^{\ddagger}$ and Richard A. Glennon ${ }^{*, \dagger}$

${ }^{\dagger}$ Department of Medicinal Chemistry and ${ }^{\ddagger}$ Department of Physiology and Biophysics, Virginia Commonwealth University School of Pharmacy, Richmond, Virginia 23298, United States

Figure S1. Relationship between the reported DAT transporter binding data of tMP analogs $(\mathrm{X} \text {-axis })^{11}$ and their $\left[{ }^{3} \mathrm{H}\right] \mathrm{DA}$ reuptake data $(\mathrm{Y}$-axis $) ;{ }^{7} \mathrm{r}=0.98, \mathrm{n}=25$. 


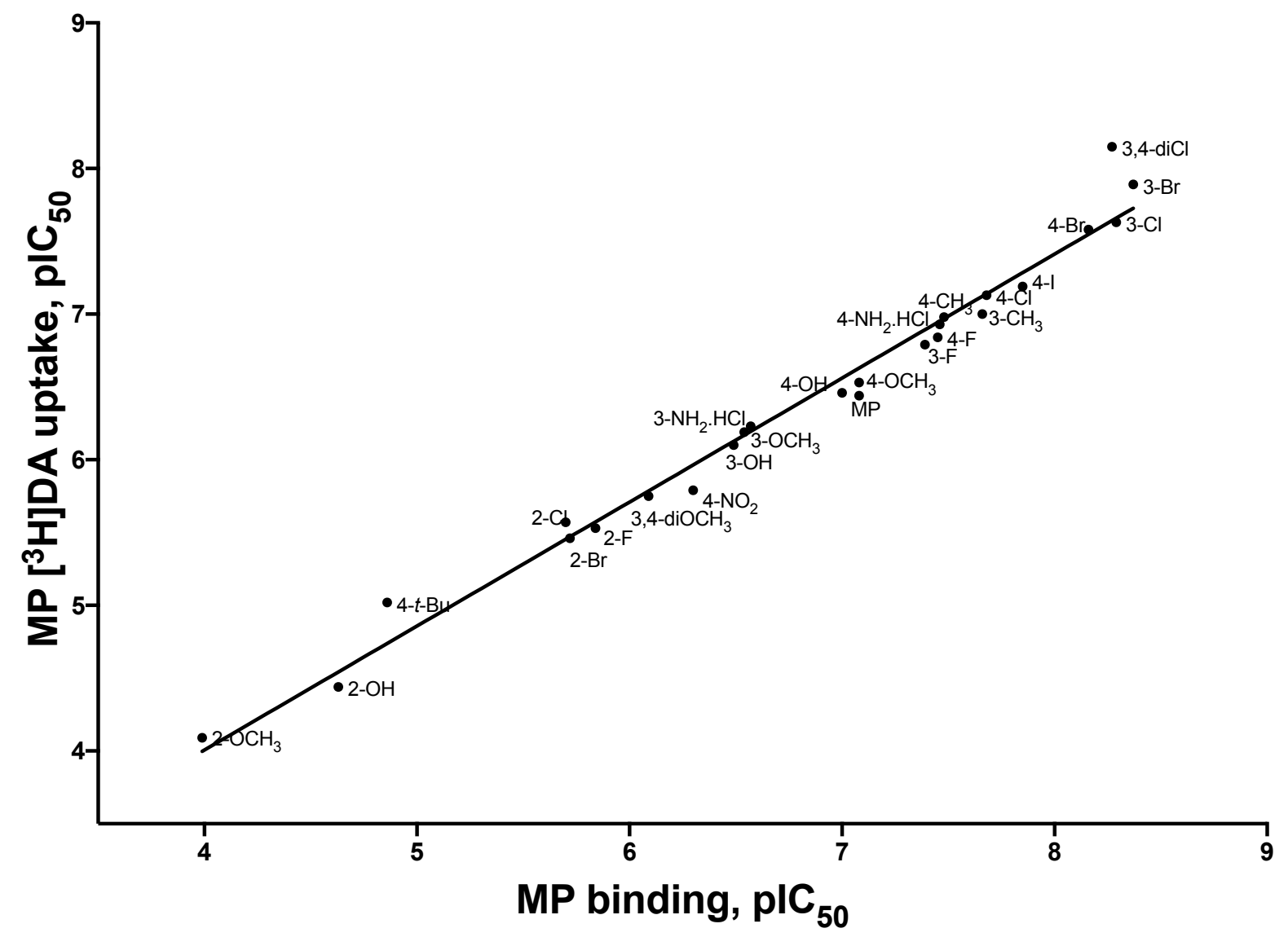

Figure S1. Relationship between the reported DAT transporter binding data of tMP analogs $(\mathrm{X} \text {-axis })^{11}$ and their $\left[{ }^{3} \mathrm{H}\right] \mathrm{DA}$ reuptake data $(\mathrm{Y}$-axis $) ;{ }^{7} \mathrm{r}=0.98, \mathrm{n}=25$. 